\title{
Autonomia e Trabalho Informacional: 0 Teletrabalho
}

\author{
Cinara L. Rosenfield ${ }^{\mathrm{I}}$ \\ Daniela Alves de Alves ${ }^{\text {II }}$
}

'Professora do Departamento de Sociologia e do Programa de Pós-Graduação em Sociologia da Universidade Federal do Rio Grande do Sul (UFRGS). Porto Alegre, RS, Brasil. E-mail: rosenfield@uol.com.br

"Professora do Departamento de Ciências Sociais da Universidade Federal de Viçosa. Viçosa, MG, Brasil. E-mail: alvesautomatic@gmail.com

\section{A SOCIEDADE DA INFORMAÇÃO}

U m contexto de precarização e flexibilização do emprego associado a mudanças na organização do trabalho nas sociedades capitalistas impõe um novo padrão de implicação no trabalho por parte do trabalhador. O trabalho - como padrão, o que não significa a inexistência de trabalho taylorista, precário, penoso ou embrutecedor - tornou-se mais variado e mais complexo, seu conteúdo e sua natureza tornaram-se mais ricos, devido a uma demanda maior de investimento subjetivo e de mobilização da inteligência. $O$ trabalho tornou-se mais instigante e, em muitos casos, imaterial. É possível, pois, supor que esse quadro represente ganhos para os trabalhadores, já que o trabalho tornou-se mais interessante e flexível.

O objetivo deste texto é discutir o significado da autonomia do trabalho imaterial - que supõe a reflexão, a concertação de saberes e de observações, a troca de informações - ligado às tecnologias de informação e comunicação (TICs), mais especificamente o teletrabalho. As reflexões aqui presentes estão associadas a pesquisas empíricas realizadas junto a teletrabalhadores - assalariados e/ou por conta própria, que trabalham parcial ou integralmente em domicílio, em Lisboa (Portugal), em São Paulo, no Rio de Janeiro e em Porto Alegre (Brasil) -, as quais totalizam 51 entrevistas, feitas em 2004 e $2005^{1}$.

DADOS - Revista de Ciências Sociais, Rio de Janeiro, vol. 54, no1, 2011, pp. 207 a 233. 
Em estudos anteriores realizados junto a operadores da indústria de produção, pôde-se constatar mudanças que apontavam exigências de mobilização subjetiva dos trabalhadores, com o propósito de atingir a correta execução de suas responsabilidades, o que vem a constituir um quadro de autonomia outorgada (Rosenfield, 2003) ${ }^{2}$. A antiga organização do trabalho taylorista ou fordista viu-se diante da necessidade de renovação, a fim de dar respostas a outro tipo de exigência: para garantir qualidade e competitividade, agora em escala inédita, o trabalho do operário industrial deve integrar a compreensão da tarefa, de maneira a possibilitar um trabalho de concertação e de troca de informações e saberes não só no momento de sua concepção, mas também no de sua execução. Se a autonomia, historicamente, sempre se impôs como elemento constitutivo do trabalho, mesmo quando o paradigma taylorista lutava por eliminá-la ou neutralizá-la, a fase pós-taylorista do capitalismo, pela primeira vez, toma a autonomia como meta e como elemento a ser gerido, em vez de suprimido. Esta seria a nova face da dominação do capital: é mister que o trabalhador se identifique pessoalmente, que se mobilize subjetivamente, que lance mão de suas capacidades psíquicas e relacionais para bem executar seu trabalho. A essas conclusões, acrescentamos aquelas relativas à autonomia no trabalho nas ocupações vinculadas às TICs. Diante de um novo paradigma tecnológico característico da era da informação (também denominada nova economia, capitalismo cognitivo, sociedade em rede ou sociedade informacional, segundo as diferentes abordagens), trata-se de analisar as novas maneiras de trabalhar e as margens de autonomia no trabalho que lhes acompanham. Se a autonomia no trabalho industrial é outorgada, já que traduz seu sentido instrumental, ou seja, é instrumento de coordenação das relações de trabalho e visa a atingir um objetivo econômico de gestão da produção, na busca de inserir no processo de trabalho os elementos que não podem ser prescritos, como a concertação e a mobilização subjetiva, trata-se aqui de confrontá-la à autonomia no trabalho ligado às TICs. Essas tecnologias, a priori, exigiriam maior qualificação e competência em suas tarefas de natureza "inteligente" e imaterial, o que apontaria redução da divisão do trabalho entre os que o concebem e os que o executam e maior margem de autonomia em sua realização. A chamada sociedade da informação remete não apenas e estritamente ao trabalho no setor de informação e telecomunicação, pois a presença e as potencialidades das TICs transformam as formas de operacionalizar, de gerir e de trabalhar nas mais diversas atividades. O modelo de empresa em rede, nas mais variadas áreas de 
atividade, por exemplo, possibilita a inclusão ou a exclusão de novos componentes, em qualquer tempo ou local sem grandes custos, e a interatividade em tempo real com fornecedores, clientes, subcontratados ou empregados; favorece maior flexibilidade, interação descentralizada, de fácil modificação, e, simultaneamente, maior controle sobre as atividades da empresa; e propicia a personalização da produção e dos serviços, segundo as necessidades de cada cliente (Castells, 2004).

O conceito de paradigma tecnológico cunhado por Castells ajuda a compreender a essência da transformação tecnológica atual, na medida em que esta interage com a sociedade e a economia. Os aspectos centrais desse paradigma, no conjunto, formam a base material da sociedade da informação: 1) a informação é a matéria-prima do novo paradigma; 2) como a informação é parte fundamental da atividade humana, os novos meios tecnológicos moldam diretamente a esfera da existência individual e coletiva; 3) a lógica das redes envolve qualquer tipo de relações usando as novas tecnologias de informação; 4) o paradigma tecnológico da informação é baseado na flexibilidade; e 5) as tecnologias específicas tendem a convergir para um sistema altamente integrado.

Os autores reunidos em torno da tese do capitalismo cognitivo (Azaïs et alii, 2001; Galvão et alii, 2003) sustentam que, principalmente em função do surgimento e da integração das novas TICs, inaugurou-se uma nova etapa na história da economia capitalista: o capitalismo cognitivo, em oposição ao capitalismo industrial. Nesse "novo capitalismo", a origem do valor não estaria mais na produção de bens homogêneos e reprodutíveis, característicos do modelo fordista de produção; agora, no modelo pós-fordista, a inovação (a produção do "novo") se torna o principal fator de valorização. Não se trata de determinismo tecnológico, mas da percepção de que o novo é menos os próprios objetos técnicos do que os motivos, as lógicas de acumulação e valorização social, no sentido de que toda a sociedade se mobiliza em direção à inovação e à acumulação de conhecimentos.

Quando está em jogo a produção de conhecimentos, como é o caso do capitalismo cognitivo, a cooperação não pode mais ocorrer nos marcos fordista-taylorista, ou seja, por meio da cooperação passiva, estática, garantida pelo encadeamento sequencial e pela adição de tarefas elementares e de funções. A cooperação para a produção de conhecimentos é consubstancial à atividade criativa, marcada pela comunicação 
horizontal não programada e por um trabalho coletivo, cooperativo e reticular, para além do controle hierárquico. Além disso, a mercadoria conhecimento apresenta características que a diferenciam de outras mercadorias do capitalismo, inclusive no que se refere ao cálculo do valor, impossível de ser feito com base na teoria marxista do valor ${ }^{3}$, o que abre uma série de controvérsias na teoria econômica clássica e na teoria da alienação.

Portanto, a passagem do capitalismo industrial para o capitalismo cognitivo não representa a centralidade do conhecimento como força produtiva, e sim o conhecimento enquanto, simultaneamente, recurso e produto desincorporado, o que traduz a passagem de um regime de reprodução a um regime de inovação.

\section{O TELETRABALHO E A AUTONOMIA NO TRABALHO INFORMACIONAL}

Se a autonomia e a natureza coletiva do trabalho passam a ser intrínsecas à nova organização do trabalho industrial pós-fordista, a nova ordem é "ser sujeito", trabalhar, se engajar e cooperar. A autonomia demandada ao trabalhador implica o desdobramento das atividades desde o fazer até a compreensão do que é feito (Terssac, 1992; Durand, 2004).

O conceito de autonomia parece-nos igualmente servir para a análise da sociedade informacional (Brey, 1999). O trabalho ligado às TICs é considerado de natureza autônoma, inteligente e relacional. A fim de refletirmos sobre essa questão, discutiremos os conceitos de autonomia e de autonomia no trabalho. Em seguida, exporemos a noção e as implicações do teletrabalho, objeto empírico que escolhemos como emblemático do trabalho informacional por traduzir um esforço conceitual de desenvolver e aprimorar definições, dadas as dificuldades de precisão diante da diversidade de suas configurações empíricas. Por fim, analisaremos a autonomia especificamente no teletrabalho, expondo dois polos-tipo de teletrabalhadores: aqueles que apresentam um engajamento individualizante virtuoso e os que mostram um engajamento precário no teletrabalho e no trabalho informacional de maneira mais geral.

\section{Autonomia: O Conceito}

A autonomia individual, em seu sentido filosófico, pode ser compreendida como autogovernança, autodeterminação, habilidade de constru- 
ir objetivos e valores próprios, liberdade de fazer escolhas e planos, e agir em conformidade com tais valores e objetivos. Isso leva à realização de si, condição para construir uma vida com significado. A autonomia individual é condição para a concepção do ser humano em situação de equidade, de igualdade. Sem ela, o homem não pode funcionar como igual na vida moral.

Ainda em seu sentido filosófico, a autonomia associa-se à noção de liberdade enquanto autodeterminação, possibilidade de escolha ou ausência de interferência. Mas a liberdade remete a uma "ideia de responsabilidade diante de si mesmo e da comunidade: ser livre quer dizer, neste caso, estar disponível, mas estar disponível para cumprir certos deveres. Desde o começo, portanto, a noção de liberdade parece apontar para duas direções: uma, a de um poder fazer; e outra, a de uma limitação" (Ferrater Mora, 2001:1734).

Autonomia não significa liberdade absoluta, pois, remetendo-a ao campo dos valores - onde justamente integraliza seu sentido, já que a busca por ela situa-se dentro de uma lógica de valores e de conquista de sentido-, é preciso ter claro que ela se insere numa "comunidade de valores", o que a torna, sempre e em alguma medida, heterônoma.

Segundo a hipótese desenvolvida por Castel em sua entrevista a Haroche (Castel e Haroche, 2001), o indivíduo, para existir enquanto indivíduo, deve dispor do que ele chama de suportes: recursos ou capitais no sentido de Bourdieu -, o que significa dispor de reservas relacionais, culturais, econômicas etc.; suportes sobre os quais o indivíduo pode se apoiar para lançar mão de condições de possibilidades de desenvolver estratégias individuais. Assim, os suportes são condições de possibilidade para tornar-se um ser individual: "Existir positivamente como indivíduo é, parece-me, ter a capacidade de desenvolver estratégias pessoais, dispor de certa liberdade de escolha na condução de sua vida porque não se está na dependência do outro" (idem, ibidem:48, tradução livre).

A teoria do reconhecimento (Taylor, 1994; Honneth, 2003; Fraser, 2001; Fraser e Honneth, 2003) traz uma importante contribuição para que se compreenda a dimensão social dos processos identitários e de construção da autonomia individual. Segundo a argumentação de Honneth (Fraser e Honneth, 2003), são três as esferas do reconhecimento: dedicação emotiva, respeito cognitivo e estima social. Para os indivíduos poderem dispor de suas autonomias individuais, é preciso que sejam 
reconhecidas socialmente suas necessidades, sua igualdade legal e/ou suas contribuições sociais, pois assim eles conseguem desenvolver uma autorrelação marcadapor autoconfiança, autorrespeito e autoestima.

Isso significa, por um lado, um processo de individualização ${ }^{4}$, na medida em que as chances de expressão, legitimação e reconhecimento de diferentes facetas da personalidade do sujeito aumentam, mas, por outro, significa igualmente um processo de inclusão social, ao inserir o sujeito num círculo igualitário composto por todos os membros da sociedade. Ambos os processos indicam possibilidades de aumento do reconhecimento social. A integração social dá-se por meio de relações de reconhecimento que confirmam e reconhecem as diversas facetas da personalidade dos sujeitos e leva-os a se tornarem membros da sociedade (inclusão social): "O progresso nas condições de reconhecimento social surge nas duas dimensões de individualização e inclusão social: ou novas partes da personalidade são abertas ao reconhecimento mútuo, e então surge a extensão da individualidade social confirmada; ou mais pessoas são incluídas nas relações existentes de reconhecimento, de forma que o círculo de sujeitos que reconhecem uns aos outros cresce" (Fraser e Honneth, 2003:186, tradução livre).

A autorrealização individual só encontra condições asseguradas socialmente na experiência do reconhecimento intersubjetivo da autonomia individual, das necessidades específicas e das capacidades particulares.

A teoria do reconhecimento social permite alçar os processos identitários a uma dimensão social, converte as questões da autonomia individual em questões de natureza social, tornando-a uma categoria relacional e intersubjetiva. De acordo com Honneth, os sujeitos esperam da sociedade, acima de tudo, reconhecimento de suas demandas identitárias. Assim, a experiência de injustiça social dá-se quando aspectos da personalidade - que se acredita possuírem direito ao reconhecimento são desrespeitados. A autonomia individual tem por "objetivo" a possibilidade de uma "formação identitária". Logo, a igualdade entre os sujeitos se materializa na formação identitária pessoal, que é dependente das relações de reconhecimento mútuo. As relações sociais de reconhecimento são, portanto, o ponto de referência para a concepção de justiça social. Possibilitar o desenvolvimento individual e a autorreali- 
zação dos sujeitos constitui o verdadeiro objetivo (ou demanda) de um tratamento igualitário entre os sujeitos nas nossas sociedades.

\section{A Autonomia no Trabalho}

A autonomia no trabalho restringe o conceito filosófico de autonomia: como falar em autogovernança e autodeterminação, seja para o trabalho assalariado ou para o independente, ambos subordinados às demandas e ao ritmo do mercado? Que dimensão da autonomia é possível no trabalho, considerando-se que, em última instância, no capitalismo, ele é meio da racionalidade instrumental para a produção de riquezas, rendimento e lucro, e, portanto, teria como objetivo, antes de tudo, atingir o máximo de eficiência na produção de riquezas econômicas (Méda, 1999a, 1999b)?

A autonomia no trabalho integra: 1) uma dimensão operacional ligada às exigências funcionais, operacionais, que remetem à organização do trabalho; 2) outra identitária, marcada pela busca de afirmação de si, de liberdade, de realização, conforme a ideia já desenvolvida de um individualismo-emancipação; e 3) e ainda uma dimensão social - e para tal nos apoiamos na teoria do reconhecimento de Honneth -, uma vez que a individualização e a inclusão social são os dois componentes dos processos de reconhecimento social.

Em termos concretos, a autonomia no trabalho traduz-se por: autodeterminação do trabalhador e sua responsabilidade ou liberdade para determinar os elementos de sua tarefa, bem como o método, as etapas, os procedimentos, a programação, os critérios, os objetivos, o lugar, a avaliação, as horas, o tipo e a quantidade de seu trabalho. Autonomia remete ao controle sobre todos esses elementos ou sobre alguns deles.

Em termos teóricos "puros", a autonomia no trabalho é uma quimera, pois se opõe à heteronomia e à necessidade; a autonomia de uma atividade marcada pela necessidade é condenada a permanecer formal. Gorz (1988) afirma serem autônomas as atividades que são, por elas mesmas, seu próprio fim. O sujeito faz, nessas ações, a experiência de sua soberania e se realiza como pessoa. O caráter heterônomo das atividades profissionais, independentemente de se tratar de trabalho assalariado ou por conta própria, e a natureza produtivista do trabalho impediriam o desenvolvimento da autonomia. 
No trabalho industrial, a autonomia outorgada impõe uma socialização caracterizada pela não coincidência entre o indivíduo-sujeito e seu ser social; e é essa coincidência, a partir de então impossível, que está na origem da autonomia individual e de toda a criação cultural. O indivíduo é condenado a viver a dualidade de ser ele mesmo (l'être-soi) porque ele precisa ser ele mesmo - e, simultaneamente, responder às exigências sociais do trabalho, que demandam "uma maneira de ser ele mesmo" no trabalho (le devoir être). Na realidade, essa dualidade o impede, em parte, de ser ele mesmo (l'être-soi).

Se o trabalho é sempre subordinado e/ou dependente - seja a um chefe, a uma demanda, ou, ainda, a um mercado-, por que indagar-se sobre a autonomia no trabalho? Primeiro, porque o discurso dominante é o de que as novas formas de trabalhar (inteligentes, autônomas, engajadas, cooperativas etc.) representam ganhos para o trabalhador, na medida em que indicam a superação da tradicional divisão do trabalho entre os que as concebem e os que as executam. Segundo, porque o conceito de autonomia no trabalho permite pensar simultaneamente: 1) a dimensão operacional (controle sobre alguns elementos do trabalho); 2) a dimensão identitária (o trabalho possibilitaria um retorno sobre o homem capaz de conferir a ele um sentido; o trabalho tem papel importante no processo de elaboração da imagem que o ator social faz de si mesmo e seu comprometimento e sua cooperação resultantes de sua integração com o trabalho o engajam no futuro coletivo); 3) a dimensão social (o desenvolvimento identitário do sujeito - particularmente por meio do trabalho - e seu reconhecimento social são condições para sua inclusão num círculo de iguais, numa sociedade moralmente justa; sua ação torna-se uma manifestação de sua própria autonomia, respeitada pelos outros mediante o reconhecimento de seu aporte). A riqueza do conceito de autonomia reside em articular o trabalho ao mundo dos valores, por meio do qual o trabalho combina o individual e o coletivo, o operacional e o identitário, o individualismo-emancipação e o individualismo-fragilização, a individualização (ou individuação, conforme Enriquez, 1997, 2000) e a inclusão social.

O trabalho informacional, com seu caráter imaterial (Lazzarato e Negri, 2001), condensaria, a priori, maiores margens de autonomia uma vez que, por tratar-se de uma mobilização de conhecimentos e concertação de saberes, reduz as possibilidades de controle externo-, assim como maior investimento e liberdade pessoais na execução dos processos necessários à construção de um produto imaterial. O teletra- 
balho e a flexibilidade que o acompanha parecem ser objetos privilegiados na análise da autonomia desse tipo de trabalho.

\section{O Teletrabalho}

Propomos, aqui, repensar conceitualmente o teletrabalho (Rosenfield e Alves, 2006), com base no que foi verificado na realidade empírica.

O Electronic Commerce and Telework Trends: Benchmarking Progress on New Ways of Working and New Forms of Business across Europe (EcaTT), relatório referente a dez países da União Europeia, liderado pela organização alemã EMPIRICA, expõe a seguinte definição: "Teletrabalhadores são aqueles trabalhadores que trabalham de forma computadorizada (com um computador), distanciados do negócio de seu empregador ou da pessoa que os contrata e que transmitem os resultados de sua atividade por uma ligação de telecomunicação" ${ }^{5}$ No entanto, o teletrabalho é uma categoria de difícil definição. Muitas variáveis e suas combinações abrem em demasia o leque de definições possíveis. A falta de uma conceituação precisa sobre o que é o teletrabalho e sobre quantos são os teletrabalhadores faz do conceito mais uma construção ideológica da realidade ou, no máximo, uma tentativa de descrição dos diversos tipos ou modalidades de teletrabalho existentes. É possível assegurar que todas as diferentes conceituações estão certas, o que demonstra ideias fortemente contraditórias. Há pessoas trabalhando em casa, com o consentimento de seu empregador, para evitar deslocamentos; há pessoas trabalhando de maneira autônoma, seja em casa, seja em telecentros; há mulheres trabalhando em seus computadores porque não têm como deixar os filhos; há alguns teletrabalhadores que se acham explorados, mal pagos e sem reconhecimento, outros são altamente qualificados e têm seu trabalho reconhecido; há teletrabalhadores em instituições públicas e privadas; há pessoas trabalhando em casa que usam "acidentalmente" seus computadores (não são sua principal ferramenta), como arquitetos ou tradutores; e há muitas pessoas que trabalham normalmente fora de suas casas e completam o trabalho em casa, na forma de sobretrabalho (por transbordamento), sem receber o pagamento de hora extra. Para completar, fax, celular, laptop e internet tornam possível trabalhar de quase qualquer lugar. Mas o que interessa aqui não é a definição precisa do teletrabalho - o que, aliás, não é possível-, mas a dinâmica de suas interações (Huws, 1991). 
Em sentido restritivo, teletrabalho pode ser definido como trabalho à distância com utilização de TICs. Em sentido extensivo, utilizado pela Organização Internacional do Trabalho $(\mathrm{OIT})^{6}$, o teletrabalho deve ser conceituado quanto a diferentes variáveis:

a) local/espaço de trabalho;

b) horário/tempo de trabalho (integral ou parcial);

c) tipo de contrato (trabalho assalariado ou independente);

d) competências requeridas (conteúdo do trabalho).

Será desconsiderado por nós o elemento quantitativo, ou seja, nossa classificação de teletrabalho independerá do número de horas trabalhadas em determinada condição. Uma análise que levasse em conta tal elemento consideraria teletrabalhadores em domicílio, por exemplo, pessoas que cumprem em casa pelo menos um dia de trabalho completo por semana.

Combinando todas essas variáveis, é grande a quantidade de modalidades ou formas que o teletrabalho pode, pelo menos teoricamente, assumir, o que justifica plenamente sua qualificação de "flexível". Podemos, para fins de apoio à conceituação, identificar seis categorias de teletrabalho: 1) trabalho em domicílio, (small office home office $\mathrm{SOHO}$ ); 2) trabalho em escritórios satélites (extensões atomizadas de uma empresa central); 3) telecentros ou telecottages (estabelecimentos, normalmente próximos do domicílio dos trabalhadores ou regionais, que oferecem postos de trabalho a empregados de uma ou várias organizações ou serviços telemáticos a clientes remotos);4) trabalho móvel (fora do domicílio do trabalhador ou de seu centro principal de trabalho, como viagens de negócios, trabalho de campo ou nas instalações do cliente); 5) empresas remotas ou off-shore (call centers ou telesserviços, através dos quais empresas europeias e americanas instalam os seus escritórios-satélites ou subcontratam empresas de tele-serviços de outras zonas do globo com mão de obra mais barata, pondo em prática o chamado teletrabalho off-shore); e 6) trabalho informal ou teletrabalho misto (arranjo que o empregado faz com o empregador para trabalhar algumas horas fora da empresa). ${ }^{7}$

Porém, muitas outras combinações no interior dessas classificações foram verificadas empiricamente, o que relativiza os limites impostos pelas definições do EcaTT ou da OIT. O teletrabalho pode ser ocasional 
e não se traduzir em mudança de contrato (informal); pode ser uma forma de trabalho alternado (realizado em domicílio, com TICs, e na empresa, sem elas); ou pode se dar por transbordamento (conexão às preocupações profissionais $24 / 24 \mathrm{~h}$ e interação com diferentes formas de solicitações, como e-mail, celular, fax etc.). Existem ainda outras combinações possíveis, inclusive a do trabalho informal com o assalariado (a pessoa trabalha na empresa de dia e executa teletrabalho independente fora do horário de trabalho assalariado, preferencialmente à noite). Em suma, combinando todas essas possibilidades (em termos de local, horário e situação socioprofissional), facilmente se constatam o grande espectro de combinações possíveis e a diversidade de formas que o teletrabalho pode assumir.

Desse modo, teletrabalho não pode ser conceituado simplesmente como trabalho à distância, mas sim como um elemento das mudanças organizacionais estratégicas que apontam novas formas de trabalho flexível sustentadas por TICs. A flexibilidade pode ser indicada por vários elementos: tempo, local, contrato, subordinação e organização funcional. Há uma relação estreita entre o surgimento do teletrabalho e a propalada flexibilidade exigida pela sua organização e necessária a ela para garantir competitividade (Jaakson e Kallaste, 2010). A flexibilidade, para o empregador, traduz-se em: horários flexíveis; polivalência; aumento e redução do número de empregados conforme a demanda; e várias formas de contrato - subcontratação, meio turno, tempo determinado e trabalho em domicílio. O teletrabalho é uma dessas opções.

O teletrabalho, pois, combina-se com trabalho atípico e flexível, podendo ou não ser precário. A autonomia é eventual e está associada, geralmente, a flexibilidade quanto ao tempo e ao horário de trabalho. O teletrabalhador tem autonomia para gerir o tempo, mas, paradoxalmente, não tem controle sobre seu tempo de trabalho, pois este é determinado pelos ditames do volume de trabalho; ou seja, é preciso sempre responder às demandas de trabalho, sem restrição de tempo ou disponibilidade.

O teletrabalho, por sua prática à distância e, muitas vezes, solitária, poderia indicar formas mais diluídas de controle sobre o processo e o produto do trabalho. No entanto, essa prática propiciou o desenvolvimento de outras formas de controle externo sobre o trabalho, como monitoramento eletrônico e por resultados (exigências e metas atingidas mo- 
nitoradas pela entrega de relatórios periódicos), tarefas pré-estruturadas (de aplicação de parâmetros e ações preestabelecidas) e, em alguns casos, criação dependente (trabalho de equipe, tomada de decisão final feita pela hierarquia).

A apologia ao teletrabalho repousa sobre as perspectivas que ele oferece para: a integração de pessoas e regiões desfavorecidas e de pessoas com mobilidade reduzida; a diminuição da poluição, propiciada pelo menor número de deslocamentos; e a projeção de novos panoramas profissionais e outros campos de trabalho (Hislop e Axtell, 2007). Repousa também sobre o argumento de uma repartição mais equânime das fontes de conhecimento e da possibilidade de combinar vida privada e trabalho por meio da flexibilidade que oferece quanto ao tempo e ao local de trabalho (Chalmers, 2008).

Contudo, segundo os teletrabalhadores pesquisados, a prática do teletrabalho indica algumas dificuldades: a substituição das relações humanas pessoais e diretas por relações à distância, mediatizadas pelas TICs (a pessoa é substituída pela sua "imagem" textual, sonora ou visual, na máquina); o isolamento profissional e, no caso de assalariamento, as dificuldades de avaliação do trabalho e das consequentes perspectivas de promoção de carreira; e as dificuldades de gerir a falta de limites claros entre tempo e espaço privados e públicos (o que constitui, também e justamente, uma das principais virtualidades do teletrabalho), como trabalhar em casa aos domingos, deixar o trabalho invadir a privacidade do lar, impor as restrições quanto ao uso de espaço e de recursos aos demais membros da família e utilizar para o trabalho o mesmo telefone e/ou computador usado pela família. Esses elementos se confrontam à simples conceituação, porque o teletrabalho mostra-se fluido, flexível, adaptável e, portanto, de difícil definição.

\section{Autonomia no Teletrabalho}

A flexibilização se expressa no teletrabalho em todas as suas dimensões. Primeiro, essa é uma modalidade flexível no que se refere às relações de trabalho, pois tanto pode ser realizada sem o vínculo de emprego e de suas garantias, predominando o trabalho por projetos e de forma independente - nesse sentido, muitos teletrabalhadores são empresários individuais, autônomos ou informais, e, portanto, parcial ou integralmente sem vínculo de assalariamento - como pode ser realizada 
por trabalhadores assalariados com vínculo empregatício, predominando o tempo parcial de trabalho em domicílio.

Segundo, a organização do processo de trabalho é marcada pela flexibilidade temporal e espacial. Se o contato tradicionalmente estabelecido entre o cliente (que pode ser o empregador) e o profissional tinha limites de tempo e espaço, como o tempo da jornada, os horários socialmente estabelecidos para o contato telefônico e os espaços presenciais, a tecnologia informacional permite uma relação flexível/elástica com o tempo, já que o trabalho pode ser produzido a qualquer tempo e em qualquer espaço e pode ser armazenado virtualmente ou, também desse modo, enviado para o cliente. Esse aspecto da flexibilidade é encontrado tanto no teletrabalho por conta própria como no assalariado.

Terceiro, a flexibilidade também diria respeito tanto à maior liberdade de negociação entre trabalhadores e empregadores, no caso dos teletrabalhadores sob contrato de trabalho, quanto entre trabalhadores e clientes, no caso daqueles por conta própria. Devido ao perfil mais independente, em tese, dos indivíduos designados para o teletrabalho no regime de assalariamento, a estes é atribuída a habilidade de gerir, conjuntamente com as chefias, sua força de trabalho, suas metas, sua qualificação em caráter continuado e sua carreira, postura naturalmente presente no teletrabalho por conta própria. Pressupõe-se que essa postura só possa ser assumida integralmente por trabalhadores altamente comprometidos com sua atividade, portanto, engajados. $\mathrm{O}$ engajamento é, pois, a priori, uma dimensão da autonomia no trabalho. Igualmente, o trabalhador por conta própria negocia diretamente com o cliente a cada demanda, podendo ou não aceitar as condições propostas, e é levado a gerir seu trabalho de maneira independente.

O engajamento no teletrabalho é explicado pela imagem positiva da disposição individual para essa modalidade de trabalho flexível. Flexibilidade e individualização seriam produtos de um agenciamento coletivo, envolvendo os teletrabalhadores, seus clientes, a gestão das empresas, as TICs e tantos outros elementos e agências. Trata-se, assim, de um "engajamento individualizante" ${ }^{8}$, que significa, ao mesmo tempo, emancipação e subordinação, decorrentes de um comprometimento pessoal com o trabalho. Tal engajamento remete ao indivíduo como autor de seu próprio trabalho e gestor de seu próprio controle, comprometido com os resultados de sua atividade e responsável direto por eles. Todavia, mesmo assim esse indivíduo fica submetido a me- 
tas e prazos, estabelecidos pela empresa, caso seja assalariado, ou pelos clientes, caso seja um teletrabalhador por conta própria.

O engajamento individualizante pressupõe uma postura ativa do sujeito em relação ao trabalho. Portanto, desloca a perspectiva do controle típico do taylorismo em dois sentidos: no sentido do lugar do qual emana o controle sobre o trabalho e no sentido de "sobre o que" age tal controle. Em primeiro lugar, no teletrabalho aqui estudado, o controle não está localizado em um centro de comando, representado por supervisores e cronometristas, nem se encontra no interior do indivíduo, por processo de socialização ou inculcação; o controle é fruto de uma correlação de forças que envolve metas, prazos e resultados, mas também escolha individual e flexibilidade. A promessa implícita é que a postura do trabalhador engajado garante maior adaptabilidade às circunstâncias flexíveis e às circunstâncias instáveis do mercado, das relações de trabalho e do processo de trabalho. Neste artigo, propomos classificar os teletrabalhadores em dois tipos principais, aqueles cujo engajamento individualizante é potencialmente virtuoso e aqueles cujo engajamento individualizante é potencialmente precário. Nosso objetivo é distanciarmo-nos dos dois polos comumente utilizados para combinar teletrabalho e assalariamento ou teletrabalho e independência, a saber: não ser assalariado é o pelos defensores do teletrabalho, uma condição desejável e positiva, na medida em que amplia a autogestão da renda, da carreira, dos empreendimentos individuais, enquanto, para seus críticos, o assalariamento é condição necessária para a conquista de garantias e segurança no trabalho, sendo a independência associada à precariedade. Como a concepção de engajamento pressupõe a relação entre autonomia e subordinação, tratamos cada tipo de engajamento como processo inacabado, no qual frequentemente há alternância entre uma condição e outra. Entre um polo mais virtuoso e outro mais precário ou frágil, há um continuum de muitas outras situações socioprofissionais.

O engajamento individualizante virtuoso refere-se à situação em que se encontram teletrabalhadores com alta remuneração, alto desempenho especializado e constante desenvolvimento de competências. Nessa situação socioprofissional, os efeitos da precarização são amenizados, na medida em que é maior o reconhecimento profissional, são melhores as condições de concorrência e são menos deletérios os efeitos da insegurança. Trata-se do que Singly (2005) denomina individualismo-emancipação. Os teletrabalhadores cujo engajamento é virtuoso 
sentem-se reconhecidos, pois usufruem de respeito cognitivo e estima social.

Para os trabalhadores independentes ou por conta própria, o engajamento virtuoso é possível quando a responsabilização individual pela conquista de certa segurança profissional e de rendimentos é compensada por outros fatores relacionados a reconhecimento profissional e autonomia no trabalho. Ou seja, há teletrabalhadores que consideram os altos rendimentos, o acréscimo de liberdade e autonomia na condução do trabalho e seu reconhecimento autoral compensadores da ausência de garantias formais. Para os teletrabalhadores por conta própria engajados de forma virtuosa, o emprego tradicional, subordinado, é associado à opressão, ao controle e à falta de liberdade, enquanto o teletrabalho é associado à autonomia e à liberdade. Logo, a autonomia é identificada pelos teletrabalhadores nas escolhas profissionais, nos empreendimentos individuais em formação profissional, na escolha de parceiros, no exercício de negociação com clientes, na gestão financeira do negócio e no uso flexível do tempo. A liberdade do uso do tempo é relatada pelos entrevistados como o principal ganho do teletrabalho, ao permitir que assumam a gestão dos tempos de trabalho e não trabalho e possam, assim, dedicar-se a atividades lúdicas, esportivas ou afetivas que ultrapassam a dimensão unicamente profissional. Encontram-se nesse grupo, por exemplo, os tradutores especializados em um autor específico ou em manuais de equipamentos médicos e os desenvolvedores de softwares específicos. Mas também podem ter engajamento virtuoso teletrabalhadores capazes de desenvolver produtos e serviços em vários meios, articulando competências diversas dentro de uma rede de colaboradores, como, por exemplo, um webdesigner que trabalha sob demanda agregando colaboradores flutuantes dependendo do tipo de projeto a ser realizado: planejamento de ambientes/exposições, identidade visual (divulgação, posicionamento de mercado, kit para eventos), projeto gráfico (decoração, livro), website institucional etc.

Além disso, nem todos os teletrabalhadores entrevistados atribuíram ao emprego assalariado formal a capacidade de assegurar estabilidade e segurança. As práticas e os discursos que atribuem ao indivíduo a responsabilidade de assegurar privadamente serviços que seriam de responsabilidade social atingem tanto os teletrabalhadores por conta própria quanto os assalariados. Alguns teletrabalhadores por conta própria driblam a insegurança assumindo uma variedade de ativida- 
des e projetos simultâneos, assegurando, assim, maior rendimento e competitividade.

Entre os teletrabalhadores assalariados entrevistados, ainda no quadro do engajamento virtuoso, também se observou um grau de autonomia relativa com relação à tomada de decisões, à solução de situações imprevistas sem consulta às chefias, devido ao fato de a maioria dos entrevistados estar locada em níveis gerenciais. Então, a autonomia relativa constatada nesses casos dever-se-ia a dois fatores: ao nível hierárquico em que se situa o teletrabalhador e à própria condição do teletrabalho, que, por ser realizado à distância dos centros de comando, pressupõe a escolha de profissionais mais independentes e engajados. Além disso, embora o ritmo de trabalho de ambos os tipos de teletrabalhadores possa ser o mesmo, os assalariados possuem algumas restrições, como as metas, os compromissos com visitas a clientes, em algumas funções, a necessidade de participar de algumas reuniões presenciais e o constante exercício de manterem-se visíveis aos superiores, mesmo não estando presentes na empresa. Entre esses teletrabalhadores encontram-se os assalariados de grandes empresas de tecnologia da informação, como a IBM.

Teletrabalhadores assalariados tendem a possuir engajamento ambíguo, mesmo quando virtuoso, visto que, apesar de realizarem seu trabalho de forma altamente comprometida e possuírem forte autocontrole e autodisciplina sobre o tempo (menos assentada na flexibilidade, como ocorre com os teletrabalhadores por conta própria), experimentam desvantagens colaterais, quais sejam: gestão articulada entre trabalho e família, que deve compatibilizar metas da empresa e demandas familiares, situação mais penosa para os que possuem filhos pequenos que exigem maior atenção; tendência ao isolamento profissional; e desvantagens competitivas em termos de distribuição de cargos e tarefas, principalmente nos casos de teletrabalho total em domicílio. Alguns deles apontam como desvantagem do teletrabalho o excesso de trabalho, que pode ser adotado, em algumas empresas, apenas como flexibilidade no cumprimento da jornada e/ou sobretrabalho em domicílio. Alguns entrevistados consideram que os dispositivos de tornar elástico o tempo são formas de intensificar o trabalho para compensar a redução das equipes, uma estratégia frequente em empresas multinacionais (Barros e Silva, 2010). 
Em ambos os casos (teletrabalho assalariado e teletrabalho independente), a autonomia é limitada pelas exigências padronizadas dos clientes e pelo caráter repetitivo e padronizado dos softwares e recursos utilizados. Apesar da redução da prescrição e do controle direto dos superiores, existem preceitos mínimos, no que se refere à satisfação dos clientes em termos de qualidade e de segurança, bem como técnicas consolidadas, as quais, no entanto, não se referem à imposição da melhor maneira de executar uma tarefa, como acontece na organização taylorista do trabalho. Conquanto dificultem a padronização de condutas, não impedem que, em algumas atividades, a tecnologia utilizada, em termos de hardware e software, seja previamente definida e formatada.

Independentemente de se tratar de teletrabalhador assalariado ou por conta própria, as atividades profissionais que envolvem criação e inovação podem ser consideradas mais livres e autônomas, pois aí também são controlados o conteúdo e os procedimentos de trabalho por parte do próprio trabalhador.

A existência de um engajamento individualizante precário entre teletrabalhadores significa que, embora estejam engajados subjetivamente no teletrabalho, alguns sofrem de maneira mais deletéria os efeitos da precarização, pelos seguintes motivos: estabelecem relações de trabalho mais informais e descontínuas; e/ou o reconhecimento profissional de seu trabalho está ausente; e/ou encontram-se em uma posição menos privilegiada em termos de qualificação e, consequentemente, de concorrência, o que torna fragilizada e insegura sua situação profissional.

Encontram-se nessa situação teletrabalhadores independentes ou por conta própria cuja insegurança não é compensada com outros fatores, ou porque os rendimentos obtidos não são bons o suficiente para compensar a ausência de salário e garantias sociais advindas do trabalho assalariado, o que está diretamente relacionado à qualificação e à competitividade do teletrabalhador, ou porque o regime de emergência reduz a autonomia na gestão dos tempos de trabalho e não trabalho. São exemplos de teletrabalhadores cujo engajamento é precário os tradutores freelancers não especializados, os desempregados e os de baixa qualificação ou os que estão há longo tempo fora do mercado de trabalho e que buscam no teletrabalho formas alternativas de renda de baixa expertise. Pode ocorrer ainda a precariedade do teletrabalhador especializado, mas inserido em um mercado restrito, como é o caso da digitali- 
zação e venda de "croquis" de desenhos de bordados ponto cruz e arraiolo.

No caso dos teletrabalhadores assalariados, ainda no âmbito do engajamento precário, a individualização pode levar ao isolamento profissional e político do trabalhador e à sua fácil substituição, quando esta se fizer necessária. Além disso, em muitas funções, o caráter formatado e controlado das tarefas (mesmo que por meio de novos dispositivos tecnológicos e organizacionais) e a pressão dos prazos relativizam os ganhos do engajamento individualizante. Teletrabalhadores nessa categoria são raros e podemos citar como exemplo aqueles assalariados em situação de invalidez ou que recebem um mínimo de assalariamento e são engajados a projetos eventuais da empresa.

A precariedade é aqui interpretada como uma condição mais ampla de fragilidade e insegurança no trabalho. Trata-se de precarização social, no sentido dado por Appay e Thébaud-Mony (1997), uma "dupla institucionalização da instabilidade", econômica e social, o que significa que ultrapassa a realidade do desemprego ou das formas inseguras de inserção e torna o trabalho e o emprego espaços marcados por instabilidade, incerteza, insegurança, imprevisibilidade, adaptabilidade e risco. Se a identificação da precariedade dá-se usualmente pela noção de pauperização, essas autoras propõem o uso do conceito com base na análise do próprio trabalho, de suas relações, condições e vivência. Assim, não se trata simplesmente de formas de instabilidade, mas de uma institucionalização e legitimação da instabilidade: "o termo precarização é utilizado, [...] [e] não precariedade, para evidenciar os processos referentes a ser colocado em precariedade, e não um estado ou estados que dizem respeito às populações vulneráveis" (idem, ibidem, 1997:512, tradução livre).

Engajamento individualizante virtuoso e engajamento individualizante precário são considerados polos de um continuum que abarca muitas outras situações socioprofissionais intermediárias, híbridas. A hibridização (Azaïs, 2004) é uma marca do teletrabalho. Mas, a rigor, embora possamos estabelecer um continuum entre os teletrabalhadores cujo engajamento é tendencialmente virtuoso e aqueles cujo engajamento é tendencialmente precário, em ambos os casos há expressão da fragilidade, ainda que em proporções e modos diferenciados em cada grupo. 
A precarização social é uma condição do capitalismo contemporâneo que abarca as condições e as experiências de trabalho de assalariados e independentes/por conta própria, o que não exclui a necessidade de investigação empírica das especificidades de cada situação socioprofissional.

Como já vimos, o conteúdo de autonomia presente no teletrabalho seria, na maior parte dos casos, relativo à gestão pessoal de alguns elementos do trabalho e a certas circunstâncias, como tempo, espaço, imprevistos e aspectos da própria vida pessoal do trabalhador. Para o grupo em que o engajamento individualizado é virtuoso, a autonomia torna-se mais completa e avança também em seu conteúdo de reconhecimento social.

A autonomia se apresenta como um estado móvel, sujeito às relações de força e tensão entre as imposições dominantes e a resistência ou adesão dos sujeitos.

\section{A Autonomia no Trabalho Informacional}

O conceito de autonomia no trabalho, repetimos, lança mão de duas questões: 1) as exigências funcionais, operacionais, deste, que remetem à sua própria organização; e 2) a busca do trabalhador por sua afirmação de si, sua liberdade e sua realização, o que remete à sua dimensão identitária e ao seu reconhecimento social. A primeira delas parece relativamente contemplada no caso do teletrabalho, uma vez que a flexibilidade inerente a ele atende às demandas de maior produtividade $e$ menores custos - a mobilidade do teletrabalho remete à flexibilidade exigida pelos métodos organizacionais, de maneira a reagir rapidamente -, e, do lado do trabalhador, reverte em maior autonomia, referente a um grande escopo de variação dos arranjos de tempo e de lugar de trabalho. Ao trabalhar por projetos ou por objetivos, o contratante estipula um prazo-limite (deadline) ou performances a atingir, e não tarefas. Esta é a combinação a que responde o teletrabalho: maior pressão por flexibilidade na utilização das competências do trabalhador, de um lado, e arranjos pessoais no tempo e local de trabalho do trabalhador, de outro. "Este compromisso ou contrato normalmente supõe certa autonomia na organização individual do tempo de trabalho e de mobilidade" (Valenduc e Vendramin, 2001:251).

A partir daí, a autonomia no teletrabalho, em suas dimensões identitária e de reconhecimento social, mostra-se como uma questão bem mais 
complexa e de difícil resposta. Vários elementos contribuem para isso: 1) é raro encontrar o teletrabalhador "puro" (que só teletrabalha), prevalece a hibridez entre trabalho assalariado tradicional e teletrabalho part time, o que associa estabilidade e flexibilidade, e é igualmente rara a precariedade em estado "puro", como o trabalhador de baixa qualificação que teletrabalha por estar desempregado e necessita criar formas alternativas de renda; 2 ) mesmo quando se trata de trabalho independente/conta própria, qualificado ou não, o trabalhador precisa garantir a constância da demanda de trabalho, o que é assegurado não somente pela qualidade de seu trabalho, mas também por sua inserção em um regime de urgência e de curto prazo característico dessas atividades, o que exige dos teletrabalhadores integrais em domicílio o esforço adicional de disponibilidade constante e de gerir, no tempo e no espaço, vida privada e trabalho - daí nossa proposta de traçar um continuum entre dois polos, o virtuoso e o precário, apresentado no item anterior, como recurso analítico; 3 ) há variadas formas de monitoramento eletrônico do trabalho, o que restringiria as formas de autonomia e autodeterminação; 4) muitas tarefas ligadas às TICs são pré-estruturadas, o que se traduz num trabalho monótono, repetitivo, sem criatividade nem iniciativa, nos moldes de um "taylorismo informacional" (Kovács, 2002); e 5) as formas e os conteúdos de trabalho são os mais variados, vão do atendente de call center ao trabalhador em domicílio, do teletrabalho móvel ao trabalho em empresas remotas ou off-shore (como o call center de uma matriz francesa operado por trabalhadores na Tunísia), e podem, ainda, combinar diferentes vínculos de trabalho-ocasional, informal, alternado, informal combinado com assalariado.

Dessa maneira, o estudo da autonomia no trabalho informacional apresenta forte similaridade com as discussões no âmbito do pós-fordismo. A sociedade da informação não cria somente empregos com alta qualificação; mesmo mantendo uma essência relacional e imaterial, este trabalho pode também ser repetitivo, rotineiro e automatizado. Nas atividades ligadas às TICs de alto controle explícito - como call centers -, o controle é simultaneamente de eficácia e de atitude, mas em tempo real. As margens de autonomia diminuem e o controle direto aumenta. Do mesmo modo, quando o trabalho exige maior qualificação e responsabilidade individual, as margens de autonomia são, geralmente, maiores. Trabalho mais qualificado e mais autônomo, muitas vezes, significa controle indireto e anterior ao próprio trabalho. 
Se é possível vislumbrar um aumento continuado das qualificações e das competências exigidas ao trabalho, não é possível confundi-lo com uma redução da divisão do trabalho entre aqueles que o concebem e aqueles que o executam, mesmo em atividades de serviços ou nas intelectuais. Mais qualificação e competência não se acompanham necessariamente de maior responsabilização estratégica e de autonomia no trabalho, mesmo que criem uma tendência a isso. Além disso, se com as TICs há alargamento ou enriquecimento das tarefas e polivalência, em algumas funções, a delegação de responsabilidades, tão propalada pelos "novos organizadores", só ocorre no interior dos procedimentos e dos quadros fixados unilateralmente pelos managers ou demandantes do trabalho - o que corrobora a noção de autonomia outorgada utilizada no contexto da sociedade industrial. Nosso argumento é que o trabalho das TICs parece reproduzir tendencialmente o modelo industrial: mais qualificação, mais autonomia; menos qualificação, menos autonomia. Mas essa tendência não é capaz de dizer tudo sobre o trabalho informacional. A realidade é bem mais complexa e ambígua, pois, se em alguns setores e atividades específicos a qualificação garante trabalhos mais inteligentes e mais responsáveis, como nas atividades criativas e inovadoras, em outros setores e atividades predominam atividades repetitivas. Na mesma direção, no que se refere às relações de trabalho, há diversidade de situações contratuais, de condições de trabalho e de horários laborais e diferenciação e individualização de trabalhadores e de relações de emprego e remuneração, inclusive dentro da mesma empresa.

Prosseguindo o paralelo com o trabalho industrial pós-fordista, na medida em que o sujeito passa a ser mobilizado para a execução do trabalho, pode-se supor, a priori, que os trabalhadores "ganham" com o enriquecimento do conteúdo e da natureza de seu trabalho. No entanto, essas transformações inscrevem-se integralmente no registro da racionalidade econômica, apesar do discurso dominante, que evoca fins de ordem social e/ou subjetiva. A situação mostra-se sob uma dimensão paradoxal: um processo permanente de busca de autonomia real por parte dos trabalhadores, que se veem, finalmente, despojados pela outorga de uma autonomia predefinida. No entanto, sua dimensão paradoxal vai ainda mais longe: se a autonomia outorgada é uma pseudoliberdade, também é um enriquecimento simbólico do trabalho, devido ao aumento de autonomia real, criatividade e iniciativa. A sociedade da informação transpõe tal paradoxo apenas parcialmente. 
Apoiando-nos em Castells (1999), argumentamos que, enquanto no taylorismo a separação se dava entre aqueles que pensavam e aqueles que executavam, na sociedade da informação vê-se a distância entre os que utilizam as informações para atingir objetivos definidos por eles mesmos - e, portanto, dispõem de autonomia - e os que sofrem os "efeitos" do mercado de trabalho e da avalanche de informações - e são reduzidos à dependência econômica e cultural. A ocupação informacional exige um elevado nível educativo por parte do trabalhador, que deve ser capaz de tomar iniciativas. A autonomia é fundamental ao trabalhador da e-economia. Além disso, é necessário que ele aprenda a aprender, ou seja, tenha a capacidade de se reciclar continuamente, sabendo o que e como aprender e como aplicar o conhecimento adquirido às atividades laborais. Castells (2004) denomina autoprogramável tal tipo de trabalho. Não obstante, mesmo a nova economia emprega também trabalho genérico, que, conforme o autor, trata-se de trabalho rotineiro, substituível e empobrecido.

O conceito de autonomia no trabalho parece-nos ser capaz de condensar essa ambiguidade e esse paradoxo, com a mesma riqueza que serviu à compreensão da realidade da sociedade industrial pós-fordista. A realidade do teletrabalho é complexa e paradoxal, pois há indícios de uma manutenção da divisão entre os trabalhos "inteligentes" e os controlados e repetitivos.

\section{CONSIDERAÇÕES FINAIS}

O trabalho informacional apresenta tamanha diversidade que impossibilita qualquer conclusão universal. Há, sim, maior autonomia no trabalho mais qualificado, como em qualquer trabalho que mobilize mais intensamente competências, habilidades e talentos. $\mathrm{O}$ trabalho repetitivo e monótono não é apanágio do trabalho produtivo industrial. Se a autonomia outorgada no trabalho industrial remete a novas formas de controle, o monitoramento eletrônico propiciado pelas TICs transforma as formas de vigilância e de controle, incluindo os próprios trabalhadores nessa tarefa, como, por exemplo, quando teletrabalhadores desenvolvem técnicas de autocontrole e autodisciplina para garantir a alta produtividade do trabalho nas tarefas flexíveis espacialmente (distantes dos centros de comando ou dos demandantes) e temporalmente (sem controle da jornada). Além disso, o trabalho com TICs e à distância nem sempre é sinônimo de trabalho criativo, pois essas tecnologias podem facilitar a utilização de tarefas pré-estruturadas 
que só necessitem ser "preenchidas". Muitas vezes, a qualidade do trabalho é medida pela precisão, como ocorre nas tarefas de tradução. No entanto, a maior parte das atividades realizadas via teletrabalho insere-se na lógica dos serviços, cujo principal objetivo é satisfazer uma necessidade ou um desejo do cliente, o que requer mobilização de informação, conhecimento e capacidade de solução de problemas. Nessas tarefas, quanto mais necessárias forem a mobilização da criatividade e a valorização da dimensão autoral, maior será a autonomia.

No caso do trabalho subordinado, são evidentes as limitações de autonomia individual. Pode-se acrescentar ainda uma combinação entre os objetivos da organização e os pessoais - ações de formação, flexibilidade de tempo e recursos para atingir as metas determinadas pela organização.

Mesmo o trabalho informacional independente, por conta própria, $a$ priori sem subordinação, acaba subordinado, em maior ou menor medida, às imposições do mercado. Cabe assinalar que a inserção do teletrabalho independente no mercado é mais individualizada, portanto, mais insegura ainda, do que a do teletrabalho assalariado, devido à ausência de garantias sociais originadas no contrato formal de trabalho e de rendimentos fixos e à demanda flutuante de trabalho. Essa insegurança reverte em fragilização social para aqueles teletrabalhadores pouco qualificados, pouco especializados e com maior número de concorrentes. Já os teletrabalhadores com habilidades e competências específicas, com menos concorrentes, com maiores rendimentos e maior capacidade de negociação com clientes a respeito de elementos do próprio produto do trabalho ou do processo, como os prazos experimentam maior engajamento no teletrabalho e maior nível de autonomia.

O trabalho imaterial - mais especificamente o teletrabalho -, produtor e consumidor de conhecimento e de informação, apresenta-se mais como trabalho flexível do que como trabalho autônomo, uma vez que a autonomia verificada diz respeito, sobretudo, a maior engajamento individualizado no trabalho, maior controle sobre o tempo e o local de trabalho, subordinados, porém, às demandas de flexibilidade, sejam do mercado, sejam das organizações econômicas, que assalariam ou consomem o trabalho informacional.

A questão central, no entanto, não pode se diluir nesses paradoxos, a busca de autonomia situa-se fora da lógica econômica e dentro de uma lógica de valores e de conquista de sentido: enquanto a autonomia ou- 
torgada ou a autonomia subordinada à lógica de mercado e de sobrevivência inscreve-se em uma lógica instrumental, a autonomia puramente operacional, subordinada à lógica instrumental, não reverte em autonomia identitária e reconhecimento, estes sim inseridos no âmbito dos valores e da realização de sentido.

(Recebido para publicação em fevereiro de 2010)

(Reapresentado em julho de 2010)

(Aprovado para publicação em janeiro de 2011)

\section{NOTAS}

1. Foram entrevistados 13 teletrabalhadores assalariados, 22 teletrabalhadores por conta própria (empresários, informais, autônomos) e 16 atendentes de call centers. Dada a particularidade da ocupação em call centers, a análise desse tipo de teletrabalho deu origem a dois outros artigos específicos (Rosenfield, 2007, 2009).

2. A autonomia é outorgada na medida em que é "concedida" aos trabalhadores, mas se constitui, ao mesmo tempo, em uma ordem a ser obedecida.

3. O que faz do conhecimento uma mercadoria diferente das demais? Em primeiro lugar, a mercadoria conhecimento não se submete à lei dos rendimentos decrescentes, isto é, os conhecimentos não são escassos. Em segundo, utilizar conhecimento não implica seu esgotamento e, portanto, seu "consumo" não é destrutivo. Em terceiro, trocar conhecimentos não implica perdê-los; a troca é uma metáfora. Em quarto, a mercadoria conhecimento não possui um valor-utilidade, este é definido dentro do processo de produção e difusão dos conhecimentos. Em quinto, o conhecimento adquire valor se for trocado e, ao mesmo tempo, socializado. E, em último lugar, o custo do conhecimento é submetido à incerteza do processo de inovação e de sua validação social.

4. Seria mais preciso falarmos em individuação, que possui um sentido de constituição do sujeito, e não em individualização, que usualmente evoca um sentido de isolamento ou fragilização (Enriquez, 1997). Poderíamos, ainda, substituir a noção de individualização pela de individualismo-emancipação (Singly, 2005).

5. Disponível em http://www.ecatt.com e http://www.sibis-eu.org. Acessado em 15/10/2005.

6. Disponível em http://www.ilo.org. Acessado em 12/5/2008.

7. . Definições disponibilizadas pelo EcaTT e por Serra (1995-1996) e adaptadas por nós em função das modalidades encontradas quando da pesquisa empírica.

8. “Engajamento individualizante na flexibilidade indica que subjetivamente o indivíduo estaria aderindo, por um lado, aos discursos e às práticas que o consideram a fonte da produtividade de seu trabalho, responsável pela gestão de seu próprio tra- 
balho, formação profissional e carreira, e, por outro, aos discursos e práticas de flexibilidade do trabalho, no sentido espaçotemporal e no sentido da organização do trabalho e do emprego. Significa também que o indivíduo seria considerado autor de seu próprio trabalho e responsável direto pelos resultados de sua atividade. Nesse sentido, o controle e a organização do trabalho não ocorreriam sem o engajamento e o comprometimento do indivíduo no trabalho" (Alves, 2008:8).

\section{REFERÊNCIAS BIBLIOGRÁFICAS}

ALVES, Daniela A. de. (2008), Gestão, Produção e Experiência do Tempo no Teletrabalho. Tese de doutorado em Sociologia, UFRGS, Rio Grande do Sul.

APPAY, R. e THÉBAUD-MONY, A. (1997), Précarisation Sociale, Travail et Santé. Paris, IRESCO.

AZAÏS, C. et alii. (2001), Vers um Capitalisme Cognitif; Entre Mutations du Travail et Territoires. Paris, L'Harmattan.

. (2004), "De-Segmentação do Mercado de Trabalho e Autonomia". Caderno de Recursos Humanos, vol. 17, no 41, pp. 173-182.

BARROS, Alexandre Moço e SILVA, José Roberto Gomes da. (2010), “Percepções dos Indivíduos sobre as Consequências do Teletrabalho na Configuração Home Office: Estudo de Caso na Shell Brasil". Cadernos EBAPE.BR, vol. 8, no 1, pp. 71-91.

BREY, Philip. (1999), “Worker Autonomy and the Drama of Digital Networks in Organizations". Journal of Business Ethics, vol. 22, pp. 15-25.

CASTEL, Robert e HAROCHE, Claudine. (2001), Propriété Privée, Propriété Sociale, Propriété de Soi: Entretiens sur la Construction de l'individu Moderne. Paris, Fayard.

CASTELLS, Manuel. (1999), A Sociedade em Rede. São Paulo, Paz e Terra.

. (2004), A Galáxia Internet: Reflexões sobre Internet, Negócios e Sociedade. Lisboa, Fundação Calouste Gulberkian.

CHALMERS, Lee. (2008), “Using IT in Work at Home: Taking a Closer Look at IT Use in Home-Located Production". New Technology, Work and Employment, vol. 23, no 1-2, pp. 77-94.

DURAND, Jean-Pierre. (2004), La Chaîne Invisible. Paris, Seuil.

ENRIQUEZ, Eugène. (1997), Les Jeux du Pouvoir et du Désir dans l'Entreprise. Paris, Desclée de Brouwer. . (2000), “Une Société Sans Résistance”. Revue L'Inactuel, Circé, no 4.

FERRATER MORA, J. (2001), Dicionário de Filosofia. São Paulo, Loyola. 
FRASER, Nancy. (2001), “Da Redistribuição ao Reconhecimento? Dilemas da Justiça na Era Pós-Socialista", in J. Souza (org.), Democracia Hoje; Novos Desafios para a Teoria Democrática Contemporânea. Brasília, UnB, pp. 245-282.

FRASER, Nancy e HONNETH, Axel. (2003), Redistribution or Recognition, a Political-Philosophical Exchange. London/New York.

GALVÃO, A. P. et alii. (orgs.). (2003), Capitalismo Cognitivo: Trabalho, Redes e Inovação. Rio de Janeiro, DP\&A.

GORZ, André. (1998), Métamorphoses du Travail et Quête de Sens. Paris, Galilée.

HISLOP, Donald e AXTELL, Carolyn. (2007), “The Neglect of Spatial Mobility in Contemporary Studies of Work: the Case of Telework". New Technology, Work and Employment, vol. 22, no 1, pp. 34-51.

HONNETH, Axel. (2003), Luta por Reconhecimento, a Gramática Social dos Conflitos Sociais. São Paulo, Editora 34.

HUWS, Ursula. (1991), “Telework: Projections”. Futures, vol. 23, no 1, pp. 19-31.

JAAKSON, Krista e KALLASTE, Epp. (2010), “Beyond Flexibility: Reallocation of Responsibilities in the Case of Telework". New Technology, Work and Employment, vol. 25, no 3, pp. 196-209.

KOVÁCS, Ilona. (2002), As Metamorfoses do Emprego, Ilusões e Problemas da Sociedade da Informação. Lisboa, Celta.

LAZZARATO, Maurizio e NEGRI, Antonio. (2001), Trabalho Imaterial: Formas de Vida e Produção de Subjetividade. Rio de Janeiro, DP\&A.

MÉDA, Dominique. (1999a), O Trabalho: Um Valor em Vias de Extinção. Lisboa, Fim de Século.

(1999b), Qu'est-ce que la Richesse? Paris, Alto Aubier.

ROSENFIELD, Cinara L. (2003), “Autonomia Outorgada e Relação com o Trabalho: Liberdade e Resistência no Trabalho na Indústria de Processo". Revista Sociologias, ano 5, no 10, pp. 350-378.

. (2007), “Paradoxos do Capitalismo e Trabalho em Call Centers: Brasil, Portugal e Cabo Verde". Cadernos do CRH (UFBA), vol. 20, no 51, pp. 447-462.

. (2009), "A Identidade no Trabalho em Call Centers: a Identidade Provisória”, in R. Antunes e R. Braga (orgs.), Infoproletários, Degradação Real do Trabalho Virtual. São Paulo, Boitempo.

e ALVES, D. A. de. (2006), “Teletrabalho”, in A. D. Cattani e L. Holzmann (orgs.), Dicionário de Trabalho e Tecnologia. Porto Alegre, UFRGS, pp. 304-307.

SERRA, Paulo. (1995-1996), O Teletrabalho: Conceito e Implicações. Universidade da Beira Interior (working paper). Disponível em http://www.bocc.ubi.pt/pag/jpserraãteletrabalho.html. Acessado em 8 de abril de 2011.

SINGLY, François de. (2005), L'Individualisme est un Humanisme. Paris, Aube.

TAYLOR, Charles. (1994), Multiculturalismo. Lisboa, Instituto Piaget.

TERSSAC, Gilbert de. (1992), Autonomie dans le Travail. Paris, PUF.

VALENDUC, Gérard e VENDRAMIN, Patricia. (2001), “Telework: from Distance Working to New Forms of Flexible Work Organization". TRANSFER, European Review of Labour and Research, vol. 7, no 2, pp. 244-257. 


\section{ABSTRACT \\ Autonomy and Information Work: Telework}

The aim of this study was to discuss the meaning of autonomy in information work, and specifically in telework. The ideas relate to empirical research with teleworkers (both hired wage-earners and self-employed), working part-time or fulltime at home, in Portugal and Brazil, with a total of 51 interviews. The article discusses the concepts of autonomy and autonomy at work, and then proceeds to expound on the notion and implications of telework. The article goes on to specifically analyze autonomy in telework (discussing two typical groups of teleworkers: those with successful self-employed work and those with precarious jobs) and in information work in general.

Key words: information society; telework; work autonomy; flexible work; individualizing involvement

\section{RÉSUMÉ}

\section{Autonomie et Travail Informationnel: Le Télétravail}

Dans cette étude, le but est de discuter le sens de l'autonomie dans le travail informationnel, spécifiquement dans le télétravail. Ces réflexions sont liées à des recherches empiriques auprès de télétravailleurs, salariés et/ou indépendants, qui travaillent à temps partiel ou complet chez eux, au Portugal ou au Brésil, formant un corpus de 51 entretiens. On y discute le concept $\mathrm{d}^{\prime}$ autonomie et d'autonomie au travail, pour exposer ensuite la notion et les implications du télétravail. On examine alors plus particulièrement l'autonomie dans le télétravail - deux pôles types de télétravailleurs y sont présentés: ceux dont l'engagement est personnalisant et vertueux et ceux dont l'engagement est précaire - ainsi que dans le travail informationnel de façon générale.

Mots-clés: société de l'information; télétravail; autonomie dans le travail; travail souple; engagement personnalisant 